\title{
Analysis on the Present Situation and Prospect of College Students' Entrepreneurship
}

\author{
Shan Jiang, Zhongtao Jiang \\ Research Institute for New Materials Technology, Chongqing University of Arts and Science, \\ Yongchuan Chongqing 402160, China
}

\begin{abstract}
With the continuous improvement of China's industrial modernization, and the optimization and upgrading of industrial structure, the employment opportunities provided by traditional industries will gradually decrease, and a large number of liberated labor will flow to the third industry. Meanwhile, with the diversification and multi-layer of people's needs, more new industries will arise and college students will be the main force of entrepreneurship in these emerging industries. This is determined by the characteristics of the college student's entrepreneurs. College students lack social experiences and project start-up funds, which makes it difficult for them to start a business in the traditional industry. But in some emerging industries, college students can strengthen their own strong points. In this paper, the current situation and existing problems of College Students' entrepreneurship were analyzed, and the entrepreneurship principles that college students should follow were pointed out. It will provide reference for the choice of future college students' entrepreneurial orientation, and the readjustment and professional setting of colleges and universities.
\end{abstract}

Keywords: College students; entrepreneurship; emerging industries; current situation; prospects.

\section{新工科背景下大学生创业现状及前景分析}

\section{姜 山, 姜中涛}

重庆文理学院, 重庆 永川 402160, 中国

摘 要: 随着我国工业现代化程度的不断提高和产业结构的优化和升级, 传统产业能够提供的 就业机会将不断萎缩, 而被释放出来的大量就业人口将涌向新兴的第三产业。在此背景下我 国教育部提出了发展建设新工科的高等教育发展战略。大学生将成为新兴行业中创业的主要 力量。这是由大学生创业者自身的综合素质特点决定的。大学生缺乏社会从业经验和项目启 动资金, 使其在传统行业创业中处于劣势。但在一些新兴行业中, 大学生创业却恰巧能够扬 长避短、发挥优势。本文分析了大学生创业的现状和存在的问题, 指出了大学生创业应该遵 循的基本原则, 为未来大学生创业方向性的选择、高校的院系调整及专业设置等提供了参考。

关键词：大学生；创业；新兴产业；现状；前景.

\section{1. 引言}

伴随全球范围内新一轮科技及产业革命的加速进行，各主要国家及经济体之间综合国力的竞 争愈演愈烈。我国正处于以新技术、新业态、新产业为特点的新经济蓬勃发展新阶段。各级 政府倡导和鼓励的创新驱动发展战略, 要求工程科技人才具备卓越的创新创业能力和跨专业 整合能力, 以助力新工科建设, 实现经济转型升级。

2016 年 9 月, 杭州 G20 峰会通过了《二十国集团创新行动计划》。该文给出的中国早期创业 活动指数为 $12.8 \%$, 高于美国、日本、德国和英国等发达国家。其中, 中国创业活动的主体 是青年，在创业者总体中的占比为 $41.7 \%$ 。但与发达国家相比，我国现阶段的第三产业在整 体产业结构中的占比仍较落后。在发达国家中第三产业在 GDP 中的占比重通常达到 70\%左右。 以 2014 年为例, 美国 75.3\%、日本 68.1\%、法国 72.4\%。我国 2016 年第三产业比重仅为 $51.6 \%$ 。 
从提供的就业数占比来看，目前发达国家的第三产业的就业人口占比达 $70 \%$ ，我国仅为 $40 \%$ 左右 [1]。2016 年, 全国在校大学生总规模达到约 3700 万人, 大学育毛入学率达到 42. 7\% [2]。 随着我国工业自动化程度的不断升级和产业结构的优化, 传统产业中能够提供的高校毕业生 就业职位会逐年递减 [3]。我国在以农林牧渔为代表的第一产业和以采矿、制造、电力、建筑 为代表的第二产业能够提供的就业人数会持续降低, 而第三产业的比重会不断增加, 主要包 括传统服务业如住宿、餐饮、运输、仓储、零售等及新兴服务业如网络、信息、软件、金融、 教育、卫生、文化、体育、娱乐等。大学生创业人群占总人数比例虽然不高, 但却社会意义 重大。

\section{2. 大学生创业的社会意义}

大学生创业者创办企业不仅可以提供更多的就业机会, 还可以不断提升我国第三产业在产业 结构中的比重, 使我国的产业结构趋向更加合理。总体来说, 创业是指创业者投入一定的资 本、智力、精力和时间等去创办属于自己的企业或事业单位的行为。就业是一个相对于创业 而言的概念, 是指就业者到别人创办的企业或事业单位去从事一份相对稳定的工作，通过劳 动换取报酬的行为。从创业与就业之间的关联性看, 创业与就业之间是相互依存的。但对于 新兴行业来说, 创业是就业的前提, 就业依赖于创业。大学生创业不仅解决了创业者本身的 就业问题, 避免和其他就业者竞争本来就有限的传统行业中的就业岗位, 而且还会随着所创 办企业的发展壮大创造更多的就业机会。例如，阿里巴巴（一下简称 “阿里”）的 2016 财年 商品即时交易总额突破 3 万亿元人民币, 预计财年将超越沃尔玛成为全球最大零售平台; 阿里 电商生态为数以万计万的大学生提供了创业的平台, 据推算, 阿里电商带来的直接就业岗位 超过一千五百万个，间接就业岗位超过三千万个。

\section{3. 大学生创业与创新的联系与区别}

创业有广义和狭义之分: 广义的创业是指社会生活各个领域里的人们为开创新的事业所从事 的社会实践活动; 狭义的创业是一个经济学的范畴, 是指主体以创造价值和就业机会为目的, 通过组建一定的企业组织形式, 为社会提供产品或服务的经济活动。如果说创业开创的是一 种实业, 创新则是指创造一种新的理念或技术。创业和创新虽然是两个概念, 但两者在本质 上是一致的, 或者说两者具有统一的本质属性: 内涵上的相互包容和实践过程中的互动发展 $[4,5]$ 。

3.1 创业的本质是一种创新

大学生创业最好引用创新的成果, 这样利于打破常规快速发展。创业的重点在于抓住机遇, 富有创意地整合资源, 因此创业本身就包含了一系列创新的行为总和。因此创业可以带动大 量新发明新创意的不断涌现, 催生出新的市场需求, 从而进一步推动和深化从科学到技术、 从技术到服务的不断创新。

3.2 创新的价值在于创业

创新促进创业、提升创业, 创新应该贯穿于各种组织和各种经营创业行为及活动的始终。创 新的价值就在于将潜在的知识、技术和市场机遇转化为实实在在的商品。而实现这种转化的 根本就是创业。对于企业来讲, 创新不仅是产品和技术的创新, 同时更是理念、管理以及营 销等全方位的创新。而这些创新正是一个企业不断发展壮大的核心竞争力。而对于国家而言, 创新涵盖众多领域包括文化、科技、经济、政治、军事、社会等众多领域。因此可以说人类 社会不断前进的过程就是一个不断创新的过程。

\section{4. 大学生群体创业的特殊性}

大学生创业的主体 “大学生”一词的含义包含在校大学生和大学毕业生。大学生创业者的主 要特点在于虽然接受了系统的高等专业教育, 但缺少从业经验和创业启动资金, 这就造成大 
学生创业者存在一个 “眼高手低” 的通病 [6]。事实上通过合理地选择创业项目做到因势利导, 大学生创业是可以做到扬长避短的。大学生创业应该首选那些对从业经验要求较低的新兴行 业, 大学生的创业应该体现一定的科技含量。大学生在校期间学到了最新最系统的理论性知 识，他们有着较高的理论优势，这与目前的政府扶持创办高科技企业的政策是一致的。对于 新兴产业, 技术的必要性及重要性不容忽视, 大学生创业的特色就是用富有想象力的智慧换 取资本。一些风投公司通常就是因为看中了大学生所掌握的先进理念而愿意对其进行风投的。 未接受过高等专业教育的创业者往往社会实践经验丰富, 有一定的经济基础, 但缺乏系统理 论知识，他们的创业方向主要集中在传统产业如加工制造业和传统服务业等领域。

\section{5. 大学生创业的素质特点及行业方向}

\section{1 大学生创业近年发展趋势}

麦可思研究院与中国社科院共同发布的《中国大学生就业报告》数据显示, 在过去的五年里, 大学生刚毕业就创业的比例连续从 2011 届的 $1.6 \%$ 上升到 2017 届的 3.0\%, 接近翻了一番。以 2017 年 795 万应届毕业生的总量计算，年创业大学生的数量超过 20 万。

5.2 大学生创业者的素质特点及对创业的认知定位

《中国大学生就业创业发展报告 2015-2016》数据显示, 73. 2\%的创业者在期间学习成绩排 名在前 30\%； 76.2\%有学生干部经历； $65.7 \%$ 有勤工助学经历；21.4\%是中共党员。创业者的素 质普遍较高, 多数是大学生中的精英人才。 《中国大学生就业创业发展报告 2016-2017》显 示九成以上大学生创业者有社会实践经历, 八成以上有担任学生干部经历, 这一比例比前一 年有所提升。大学生创业者正逐渐形成 “理性平和、积极向上” 的创业认知。另一项 2014 年 调查显示从专业分布看, 被调查者中经济管理类专业的学生占 $40 \%$, 理工类学生占 $32 \%$, 其他 人文类专业学生占 $10 \%$, 其他专业学生占 $18 \%$ 。从学历分布看, 被调查者中 $74 \%$ 的创业者为本 科毕业, 专科生比例为 $22 \%$, 硕士及以上比例仅为 $4 \%[7]$.

从对综合素质要求的角度看, 创业对人的综合素质和能力要求比更高。这是因为, 创业者不 仅要掌握与创业相关的专业知识和技能, 还要学会应对企业内部人财物的管理、企业外部的 市场经营活、社会公共关系, 和熟知财务、税务、金融、谈判等方面的知识和技能。因此, 大学生创业者应该大学学习期间就围绕将来创业所需要的知识和能力, 全方位地进行学习, 从而做好创业的充分准备。而对就业者而言对综合素质的要求就比较就单纯了, 他们只要掌 握与就业岗位工作要求相适应的专业知识和技能也就能胜任工作了。这是由于企业分工不断 细化, 每个人只需要胜任某种专业工作中的某一环节即可。大学生创业者对于创业的理解也 悄然发生了改变, 目前他们对创业的理解已经不仅局限于 “创办公司” 等商业行为, 七成以 上将创业理解为 “开创事业” 以及 “知识资本化” ，有八成以上能够积极对待创业失败。

5.3 大学生就业和创业的行业方向

《中国大学生就业创业发展报告 2016-2017》还揭示出信息、制造和金融是提供毕业生就业 岗位最多的行业, 国有企业仍然是大部分毕业生选择初次就业的首选, 然而最多的大学毕业 生还是进入了民营企业。毕业生就业选择最看重的因素中, 排在前 5 位的依次是发展前景、 薪酬待遇、兴趣爱好、工作稳定和工作地点, 比例分别为 46.3\%、20.9\%、9.39\%、7.61\%和 6.91\%。 报告还显示 2017 届毕业生创业领域主要集中在信息服务、教育和文化体育领域, 比例分别是 12. 4\%、10.6\%和 $10.6 \%$ 。某网络调查结果显示大学生进行自主创业的合适行业中服务业占比 最高 34\%, 快速消费品和批发零售业紧随其后, 分别达到 24\%、22\%, 选择 IT 业的只有 20\%[8]。 大学生自主创业, 最好能够选择熟知的行业, 以缩短创业熟悉期。所选的新兴行业一般应该 包含以下特点: 代表社会发展需要, 发展空间大; 对工作经验要求较低, 对系统理论知识要 求较高; 投资风险较小，资金周转较快。 


\section{6. 结语}

大学生创业者应该根据个人的综合素质特点及专业方向等选择合适的创业机会。其中创业的 机会主要指所选行业的市场潜力, 对工作经验、资金的需求程度等。高校作为培养和输出人 才的主体单位, 应该不断调整和优化内部的院系及专业设置, 根据人才市场的动态需求相应 地调整不同专业的招生人数。

\section{Acknowledgments}

This work is supported by Teaching reform projects of Chongqing University of Arts and Sciences (Grant No. 170243 and 171005), Research project of Chongqing University of Arts and Sciences (201714) and The Scientific and Technological Research Program of Chongqing Municipal Education Commission (Grant No. KJ1601117)

\section{References}

[1]. Yongze Yu, Ran Liu, Xiaozhang Yang. Study on the impact of industrial structure upgrading on total factor productivity in China. Industrial Economic Review. 2016 (4): 45-58.

[2]. Report on the quality of higher education in China. Beijing: Higher Education Evaluation Center of the Ministry of Education of China. 2016.

[3]. Jie Lu. Research on the impact of industrial structure adjustment on labor and employment. Shandong University of Finance and Economics. 2016: 14-40.

[4]. Yanchun Zhou. Review of the research on the relationship between entrepreneurship and Innovation. Productivity Research. 2009 (22): 255-256.

[5]. Xiangyang Wang. Innovation and entrepreneurship education in universities and the cultivation of innovative and entrepreneurial talents. The Science Education Article Collects. 2016 (341): $1-2$.

[6]. Zhicheng Shi, Yun Zhao. Research on the factors influencing the success factors of College Students' entrepreneurial success. Journal of Chongqing Jiaotong University (SOCIAL SCIENCE EDITION). 2014 (6): 109-112.

[7]. Shuzhen Zheng, Ying Dai, Hua Wang. Innovation venture Survey Analysis and countermeasure research in Xiamen city as a case investigation and analysis of College Students' Entrepreneurship. Journal of Innovation and Enterprise Education. 2016 (3): 53-55.

[8]. Heng Tan, Shijie Chen. A survey on the successful entrepreneurship of College Students. Economic Research Guide. 2015 (19): 200-202. 